\title{
OS CAVALEIROS DE SANTARÉM NA SEGUNDA METADE DO SÉCULO XIII
}

Mário Viana*

\section{Introdução}

Neste texto trato essencialmente do problema da distinção entre os cavaleiros vilãos e os cavaleiros de linhagem no contexto de um dos grandes centros urbanos portugueses da Idade Média. Abordo as questôes da evolução da cavalaria vilã e da sua articulação com os poderes local e central. Os percursos de três cavaleiros, Rui Pais Bugalho, João Viegas e Silvestre Peres, servem para detalhar com uma informação rica a temática da cavalaria urbana e das suas ramificaçôes.

\section{Milites}

Durante a Reconquista portuguesa a palavra milites designou uma camada superior de guerreiros especialmente ativos nas regióes de fronteira cujo desenvolvimento foi proporcional à necessidade de efetivos para viabilizar a defesa e o povoamento dos novos territórios. Esta camada dividia-se em dois grupos. $\mathrm{O}$ grupo dos cavaleiros per naturam, ao qual corresponde o duplo sentido vassálico e profissional associado a milites. E o grupo a que corresponde apenas o sentido profissional ou funcional do termo, identificado por expressões como cives milites, plebeis militibus, militibus vilanis.

No estudo dos milites um problema de base não está na comprovação da existência daquela camada, bem atestada na documentação, e aprofunda-

* Universidade dos Açores - Centro de Estudos Gaspar Frutuoso (Universidade dos Açores). Centro de História de Além-Mar (Universidade Nova de Lisboa-Universidade dos Açores).

Categorias sociais e mobilidade urbana na Baixa Idade Média, Lisboa, Edições Colibri/ CIDEHUS-UÉ, 2012, pp. 61-81 
damente estudada por Robert Durand e José Mattoso' . Está sim na distinção dos elementos pertencentes ao grupo dos cavaleiros por nascimento ou de linhagem e ao grupo dos cavaleiros vilãos, que nem sempre é possível estabelecer de forma clara.

Por vezes o contexto em que a menção a um determinado cavaleiro é feita ajuda a efetuar a distinção entre os grupos referidos. Assim, incluem-se entre os cavaleiros por nascimento os milites que pululam nas inquiriçôes de 1258 , debicando migalhas dos direitos e domínios reais. Desde logo quando o redator da ata acrescenta ao respetivo nome um locativo de origem ${ }^{2}$. Já no caso das listas de testemunhas de instrumentos tabeliónicos feitos nos concelhos do sul o termo miles recai frequentemente sobre um cavaleiro vilão. Mas, devido à inconstância antroponímica destas listas, o mesmo indivíduo pode ou não ser registado com a categoria de miles, além de apresentar combinações alternativas de nome próprio, patronímico e nome de família, ou simplesmente o primeiro destes elementos, antecedido de uma fórmula reverencial de tratamento $(\text { domnus })^{3}$. Em princípio mais clarificadoras, mas menos abundantes, são as mençōes que sugerem o contexto urbano da cavalaria, tais como militis Sanctarene ou miles Sanctarenensis ${ }^{4}$, milites Elbore ou militibus Elborensibus ${ }^{5}$, milites et uicini de Maura ${ }^{6}$, entre outros exemplos possíveis.

${ }^{1}$ Robert DURAND, Les campagnes portugaises entre Douro et Tage aux XIIe et XIIIe siècles, Paris, Fundação Calouste Gulbenkian - Centro Cultural Português 1982, pp. 531-558; José MATTOSO, Identificação de um país. Ensaio sobre as origens de Portugal (1096-1325), 3a ed., Lisboa, Editorial Estampa, 1988, vol. 1, pp. 115$-125,347-360$.

${ }^{2}$ Alguns exemplos: Alexandre HERCULANO, Portugaliae Monumenta Historica. Inquisitiones, Lisboa, Academia Real das Ciências, 1868-1977, pp. 1084 (Martininus Roderici miles de Gouviaes), 1424 (Petrus Laurencii miles de Chorenti), 1446 (Johannes de Ulvar, miles), 1470 (Petrus Pelaiz d Algozo miles), 1488 (Menendi Gomecii de Louredo miles).

${ }^{3} \mathrm{O}$ uso de dom (< domnus) está longe de ser de uso exclusivo dos cavaleiros. Em Santarém, no século XIII, encontramo-la aplicada também a membros do clero secular e regular, escrivães, mesteirais (um zapatarius, um alfaiate e um pelliparius, por exemplo), mercadores e proprietários ricos.

${ }^{4}$ João Pedro RIBEIRO, Dissertações cronológicas e críticas sobre a história e jurisprudência eclesiástica e civil de Portugal, Lisboa, Academia Real das Ciências, 1810-1836, tomo 3, n. 22 (1255: João Viegas, militis Sanctarene); Alexandre HERCULANO, Portugaliae Monumenta Historica. Leges et consuetudines, Lisboa, Academia Real das Ciências, 1856-1868, vol. 1, p. 717 (João Esteves, miles Sanctarenensis).

5 Pedro de AZEVEDO e Anselmo Braamcamp FREIRE, Livro dos bens de D. João de Portel. Cartulário do século XIII, sep. de Arquivo Histórico Português, Lisboa, 1906-1909, ns. 2 e 3 (1258: milites Elbore) e 9 (1261: militibus Elborensibus).

${ }^{6}$ Pedro de AZEVEDO e Anselmo Braamcamp FREIRE, Livro dos bens de D. João de Portel..., n. 7 (1260: milites et uicini de Maura). 
O problema da distinção entre cavaleiros por nascimento e cavaleiros vilãos coloca-se, creio, com maior premência em relação às listas de testemunhas dos documentos elaborados nos centros urbanos do sul, onde os ávidos cavaleiros de Entre Douro e Minho se deixavam atrair e misturar com os cavaleiros da terra. Porém, a prática permitia reconfigurar os grupos sempre que necessário. Por exemplo, quando reunidos, os cavaleiros por nascimento dependiam do representante militar do rei, o alcaide, enquanto os cavaleiros vilãos dependiam do adaíl, exceto se tivessem recebido cavalarias do rei, situação em que ficavam também sob a autoridade do alcaide ${ }^{7}$.

\section{Evolução da cavalaria vilã}

Outro problema de base é o da evolução do grupo de cavaleiros vilãos, cuja análise é constrangida pela interpretação como simples híbrido das categorias de nobre e não nobre que a própria origem ideológica do conceito de vilania acaba por desmentir. Detalhemos, entretanto, aquelas que penso serem as grandes fases dessa evolução.

A primeira fase, como já foi referido, é a da Reconquista, com a formação de uma elite de proprietários armados que foi uma das condições da superioridade militar cristã frente ao islão peninsular. A formação desta elite assegurou uma liderança municipal empenhada na expansão territorial e facilitou a penetração da nobreza nos núcleos urbanos da Estremadura e do sul a partir dos seus escalóes inferiores. Mas, em especial, fortaleceu o poder régio por via da necessidade de contínua manutenção dos privilégios jurídicos e fiscais gozados pelos cavaleiros vilãos, que eram afinal aquilo que eles próprios viam como o núcleo dos seus foros, bons usos e costumes.

A segunda fase, que podemos colocar por volta de 1250, corresponde ao fim das condiçôes políticas e sociais que tinham dado lugar às primeiras gerações de milites. Nas novas condições os monarcas aproveitam todas as oportunidades para aumentar os seus meios de governação. Em relação aos centros urbanos mais ricos mostram-se pelo menos tão ávidos como os nobres de Entre Douro e Minho em relação aos próprios direitos e domínios reais ${ }^{8}$. Os códigos de direito local, compostos durante o século XIII, conhecidos por Costumes, comprovam o novo quadro em que se insere a cavala-

${ }^{7}$ José MATTOSO, Identificação de um país..., vol. 1, pp. 359-360.

${ }^{8}$ Como exemplos, tendo por base as inquirições de 1258, podem ver-se, entre outros estudos, Iria GONÇALVES et al:: "O Entre Cávado e Minho, cenário de expansão senhorial no século XIII”, Revista da Faculdade de Letras, 4a série, 2 (1978) 399-440 e José MATTOSO, Luís KRUS e Olga BETTENCOURT, "As inquirições de 1258 como fonte da história da nobreza: o julgado de Aguiar de Sousa", Revista de História Económica e Social, 9 (1982), 17-74. 
ria vilā. Os Costumes de Santarém, por exemplo, cuja primeira versão conhecida terá sido composta entre 1268 e $1280^{\circ}$, já não revelam qualquer interesse em desenvolver a prestação de serviço militar a cavalo. Ligados quer à atividade legislativa estatal quer a um contexto de «superação da primitiva sociedade de fronteira ${ }^{10}$, preocupam-se, sim, na sua maior parte, com matérias de direito e fiscalidade. Compreende-se então que os representantes dos interesses dominiais e fiscais do rei (mordomo, porteiros do mordomado, saióes, almoxarife e ovençais) surjam neste texto em preponderância. Em conjunto reúnem cerca de 70 citações, sendo seguidos pelo representante militar, o alcaide, com 42 citaçōes. Em comparação, ao nível do poder local, os alvazis reúnem 35 citaçôes, os almotacés 15 e os porteiros do concelho outro tanto.

A preponderância dos funcionários régios é inevitável num quadro de crescimento do poder central economicamente suportado pelos centros urbanos. Assim, nas cidades e vilas do senhorio régio, o grupo dos cavaleiros vilãos integra-se numa elite urbana dedicada ao controlo do poder local, da qual participam também cavaleiros de linhagem, clérigos e mercadores. A formação desta elite constitui para o poder régio uma das condições da sua superioridade frente a outros poderes.

Por fim, a terceira fase inicia-se com a colocação de um marco limitativo na evolução da cavalaria vilã como instituição. Penso que esse marco corresponde à lei promulgada por $\mathrm{D}$. Dinis em $1305^{11}$ na qual o monarca reserva para si, ou para quem seu mandado tiver, a capacidade de fazer cavaleiros os homens dos concelhos. Diploma habilmente redigido, transmite a ideia de servir em comum os interesses dos concelhos e da coroa. E na verdade, os objetivos expressos interessavam às duas partes, uma vez que se procurava evitar a multiplicação de indivíduos isentos dos encargos municipais e, por outro lado, impedir o acesso dos senhores poderosos (ricos homens) ao recrutamento de cavaleiros no espaço concelhio. Mas é igualmente verdade que um terceiro e um quarto objetivos decorrem logicamente

${ }^{9}$ Zeferino BRANDÃO, Monumentos e lendas de Santarém, Lisboa, David Corazzi Editor, 1883 (edição) e Mário VIANA, "Um testemunho de direito consuetudinário municipal (1281)", Arquipélago. História, 6 (2002), 399-415 (proposta de datação).

${ }^{10}$ Cf., para a expressão, José María MONSALVO ANTÓN, "Transformaciones sociales y relaciones de poder en los concejos de frontera, siglos XI-XIII. Aldeanos, vecinos y caballeros ante las instituciones municipales", Relaciones de poder, de producción y parentesco en la Edad Media y Moderna, ed. Reyna PASTOR, Madrid, Consejo Superior de Investigaciones Científicas, 1990, pp. 132-133 e nota 39.

${ }^{11}$ Maria Teresa Campos RODRIGUES, e Nuno Espinosa Gomes da SILVA, Livro das leis e posturas, Lisboa, Faculdade de Direito da Universidade de Lisboa, 1971, pp. 202-203. Cf. J. MATTOSO, Identificação de um país..., vol. 1, p. 360. 
da aplicação da lei. São eles, a curto prazo, a limitação de crescimento da cavalaria vilã para além dos limites já alcançados, e a médio e longo prazo a redução dos seus efetivos por efeito da natural erosão biológica das famílias.

\section{Cavaleiros de Santarém}

\subsection{Percursos estudados}

De um ponto de vista metodológico, o cabal apartamento entre os dois grupos referidos depende de duas linhas de trabalho articuladas entre si: amostragens e levantamentos prosopográficos que permitam definir o âmbito e composição de cada grupo, e a produção de estudos de caso ilustrativos de percursos individuais.

Relativamente a Santarém, dentro destas duas linhas de investigação, existem já um levantamento das primeiras geraçôes de cavaleiros escalabitanos, até à primeira metade do século XIII ${ }^{12}$, e a reconstituição dos percursos de um cavaleiro por nascimento e de um outro cavaleiro, viláo, cuja cronologia se desenvolve dentro da segunda metade do mesmo século.

Rui Pais Bugalho ${ }^{13}$ é o nome de um cavaleiro identificado no Livro de linhagens do conde D. Pedro como «de um escudo e uma lança» ${ }^{14}$, fórmula que associada à alcunha de família o confirma como elemento da pequena nobreza, mais concretamente de uma família do julgado da Maia. Como tantos outros cavaleiros da região senhorial de Entre Douro e Minho, cedo terá descido para Sul, provavelmente atraído por uma fronteira em vias de desaparecimento. Não sabemos ao certo se participou nas últimas empresas da Reconquista, mas recebeu bens em Arronches (conquistada em 1261), e um seu meio-irmão obteve a alcaidaria de Marvão. Vassalo, primeiramente do infante D. Afonso, irmão de D. Dinis, passará em 1281 para a vassalagem régia. Porém, não data de então a sua ligação a Santarém, pois já em 1272 o encontramos registado como proprietário no campo de Toxe ${ }^{15}$, per-

${ }^{12}$ Mário VIANA, "Os cavaleiros de Santarém nos séculos XII e XIII", Arquipélago. História, 9-10 (2005-2006), 581-601.

13 Bernardo Maria Godinho de Sá NOGUEIRA, e Mário VIANA, "Rui Pais Bugalho, privado del-rei D. Dinis. Origens, património e carreira política”, Arqueologia do Estado. Primeiras jornadas sobre formas de organização e exercício dos poderes na Europa do Sul. Séculos XIII-XVIII, Lisboa, História \& Crítica, 1988, vol. 1, pp. 447-455.

${ }^{14}$ José MATTOSO, Livro de linhagens do conde D. Pedro, Lisboa, Academia das Ciências de Lisboa, 1980, vol. II/2, p. 165.

${ }^{15}$ Pedro de AZEVEDO) e Anselmo Braamcamp FREIRE, Livro dos bens de D. João de Portel..., n. ${ }^{\circ} 187$. Numa atraente área de policultura, próxima da vila, deno- 
tencente ao termo da dita vila, juntamente com sua mulher Urraca Eanes. A esta chama o Livro de linhagens do conde D. Pedro Urraca de Santarém, e nada mais sabemos dela ${ }^{16}$. Seria talvez filha de um mercador local, hipótese que não é totalmente gratuita, como veremos. Vizinho, por casamento, de uma vila onde os falcoeiros e trovadores não eram estranhos à nova alcáçova mandada construir por Afonso III, não é de admirar que em 1290 o rei D. Dinis trate Rui Pais Bugalho por seu açoreiro. Mas os seus serviços à coroa eram mais variados do que isso: inquiridor nas terras de Basto, desembargador tout court, testemunha de cartas régias, devisor, avaliador de propriedades, são alguns dos que estão documentados.

O percurso de Rui Pais Bugalho, já de si bem sucedido, pode-se considerar rematado de duas formas. Pelos seus filhos, Fernão Rodrigues Bugalho, casado com a filha de um importante mercador de Santarém, Afonso Guilherme ${ }^{17}$, que virá, além disso, a ser alcaide de Lisboa, e Teresa Rodrigues Bugalho, unida pelo casamento à linhagem dos Pimentéis. E pelos títulos que ostenta ou lhe são atribuídos. "Dom", claramente com sentido nobiliárquico, num instrumento de composição de 1297, entre o concelho da cidade de Lisboa e a gente do mar de Biscaia, de uma parte, em que testemunha no segundo lugar, logo a seguir ao bispo de Lisboa ${ }^{18}$. E "privado" do rei que o já citado D. Pedro, filho bastardo de D. Dinis e conde de Barcelos, lhe atribui, e que podia ser compartilhado com nobres de condição superior à sua ${ }^{19}$.

minada Assacaia, encontramos também menção a uma horta de Rui Pais Bugalho (ANTT, SMA, mç. 7, n. ${ }^{\mathrm{o}}$ 137).

${ }^{16}$ José MATTOSO, Livro de linhagens do conde D. Pedro..., vol. II/1, p. 401. Registe-se, contudo, uma Urraca de Santarém (domna Orracha de Sanctarena) num obituário do mosteiro de São Vicente de Fora de Lisboa (Maria José Azevedo SANTOS, Um obituário do mosteiro de S. Vicente de Fora. A comemoração dos que passaram deste mundo, Lisboa, Academia Portuguesa da História, 2008, p. 108).

${ }^{17}$ José MATTOSO, Livro de linhagens do conde D. Pedro..., vol. II/1, p. 326 (dona Maria Afonso, filha d' Afonso Guilherme de Santarém”). Em 1300 Afonso Guilherme, mercador de Santarém, paga 3 mil libras que tomara emprestadas do rei (ANTT, $A L M$, mç. 2, n. ${ }^{\circ} 28$ ).

${ }^{18}$ DHCL. LIM1949, n. ${ }^{\circ}$ 2; João Martins da Silva MARQUES, Descobrimentos portugueses. Documentos para a sua história, Lisboa, Instituto de Alta Cultura, 1945-1971, suplemento ao vol. 1, n. ${ }^{\circ} 15$.

${ }^{19}$ José MATTOSO, Livro de linhagens do conde D. Pedro..., vol. II/2, pp. 165 ("Rui Paaez Bugalho, que foi boo cavaleiro e privado d' el rei dom Dinis"), 392 (por exemplo: de D. Dinis, os meirinhos-mores João Simão e Nuno Martins de Chacim; do seu sucessor, Afonso IV, o rico-homem Lopo Fernandes Pacheco). 
O segundo percurso que acompanharemos é o de João Viegas, cavaleiro e vizinho de Santarém ${ }^{20}$. Os seus dados pessoais conservados desdobram-se entre 1249 e $1294^{21}$. O traço distintivo é, neste caso, o de grande proprietário. Em Santarém, uma das aldeias do termo, a Romeira, é nomeada em alternativa por Póvoa de João $\mathrm{Egas}^{22}$. No campo de Caçarabotão conduz ao longo de décadas uma persistente estratégia de aquisição que atinge no mínimo trinta parcelas. Tem vários prédios urbanos, em especial na freguesia de Marvila, e outros, rústicos, em Alvisquer, Alviela, Fairro e Horta Lagoa. Neste último local possuía uma deffensam junto do reguengo, a qual, feita inquirição pelo alcaide (pretor) e alvazis, se comprovou existir já no reinado de Afonso II (1211-1223) ${ }^{23}$. Trata-se, provavelmente, de uma cavalaria que recebeu por via do progenitor, Egas Peres ${ }^{24}$. Podem-se-lhe ainda apontar interesses esclavagistas ${ }^{25}$. Os seus interesses patrimoniais chegam, enfim, a Lisboa, onde possui bens em sete locais diferentes, com destaque para os

${ }^{20}$ Como cavaleiro de Santarém é mencionado, por exemplo, em 1255 (João Egas, miles Sanctarenencis - João Pedro RIBEIRO, Dissertaçôes cronológicas..., tomo 3, n. ${ }^{\circ}$ 22) e 1267 (João Egas, miles Sanctarenensis - ANTT, Chr. Af. III, liv. 3, fl. 20v.).

${ }^{21}$ Maria Filomena ANDRADE, “João Viegas, cavaleiro de Santarém: um percurso patrimonial", Santarém na Idade Média. Actas do colóquio 13 e 14 de Março 1998, Santarém, Câmara Municipal de Santarém, 2007, pp. 285-295. 2007. A autora apresenta a data de 1321 como limite de reconstituição do percurso de João Viegas, mas a data real do documento que cita é 1283 (ANTT, SCS, mç. 2, n. ${ }^{\circ} 67$ ). Além do mais, em 1298 mencionam-se uma adega e tendas que foram de João Egas, em Marvila (ANTT, $A L C, 1^{\text {a }}$ inc., mç. 20, n. $\left.{ }^{\circ} 17\right)$.

${ }^{22}$ ANTT, SCS, mç. 2, n. ${ }^{\circ} 73$ (1282: in loco qui dicitur Romeyra Johanjs Egee), ANTT, SCS, mç. 4, n. ${ }^{\circ} 137$ (1284: Martinho Domingues, de popula Johanjs Egee).

${ }^{23}$ ANTT, SCS, mç. 3, n. ${ }^{\circ} 87$ (1261). O termo deffensam deve ser aqui o equivalente de devesa muito frequente nas inquirições de 1258, como topónimo e como tipo de propriedade delimitada e vedada, mas que também se pode encontrar no sentido de propriedade privilegiada: Item, dixit Petrus Boy de Chavis, juratus et interrogatus, quod devesa Sancte Crucis erat de ricohomine de terra et erat devesa, et quicumque ibi intraret absque mandato pectaret domino terre $l x$. solidos. (Alexandre HERCULANO, Portugaliae Monumenta Historica. Inquisitiones..., vol. 1, p. 1528)

${ }^{24}$ Sobre as cavalarias veja-se José MATTOSO, Identificação de um país...,, vol. 1, pp. 357-360.

${ }^{25}$ Em 1282, João Egas, cavaleiro, e sua mulher Maria Martins, fazem composição com Fátima, sua sarracena, obrigando-se esta a dar-lhes cada dia de renda dezoito dinheiros, a não ir a lado nenhum, até três dias, sem seu mandado, e fugindo que lhe cortem um pé (ANTT, SCS, mç. 3, n. ${ }^{\circ} 88$ ). 
casais e vinhas do Lumiar. O filho, Estêvão Eanes, está documentado como alcaide de Óbidos, e vassalo da rainha dona Isabel, a quem pertencia a nomeação daquela alcaidaria ${ }^{26}$. Nesta condição proporciona um exemplo de mobilidade social entre as categorias vilã e nobre ocorrida à terceira geração. Continua a estratégia aquisitiva do pai mas amplia-a com propriedades de maior prestígio, duas quintas, uma no termo de Óbidos e outra no termo de Alenquer. A neta, Maria Esteves, dita Mafarra, será abadessa de Santa Clara de Santarém, e é sem dúvida a ela que se deve, em última análise, todo este memorial, incorporando os pergaminhos da família no cartório do seu mosteiro.

Mobilidade territorial e serviço régio, mobilidade social entre os escalões superior da vilania e inferior da nobreza, irradiação regional das famílias, suportada por casamentos e aquisições patrimoniais, sistemáticas ligações às instituiçōes monásticas, tais me parecem ser as linhas de força dos percursos evocados.

\subsection{Aspectos quantitativos}

Vejamos agora alguns aspetos quantitativos sobre os cavaleiros de Santarém, dentro da janela de observação considerada (1230-1300). Em primeiro lugar, é preciso chamar a atenção para o carácter dos dados utilizados. Documentação fragmentária e dispersa como a que utilizei só pode dar origem a amostragens prosopográficas e não a levantamentos sistemáticos, como é o caso dos proporcionados pelos livros de vereaçôes dos séculos $\mathrm{XV}$ e XVI. É difícil avaliar o grau de distorção dos resultados obtidos.

Assim, identifiquei um total de 139 cavaleiros, optando por classificar 50 como cavaleiros por nascimento, e 89 como cavaleiros vilãos (por vezes, em ambos os casos, com dúvidas). Em termos percentuais a proporção é respetivamente de $36 \%$ e $64 \%$. Mas tendo em conta que é provável uma inflação do número de cavaleiros vilãos, devido a identificaçōes falhadas, é mais aceitável uma proporção 40/60. As identificaçōes falhadas são inevitáveis tendo em conta a frequente insuficiência de muitas referências antroponímicas, e sobretudo o facto de mais de $60 \%$ dos cavaleiros em causa serem conhecidos apenas por um único documento. Apenas para um pouco mais de $20 \%$ dos casos podemos acompanhar os percursos destes indivíduos por períodos cronológicos superiores a uma década, beneficiando mais do cruzamento de referências.

Outro aspeto que pude estabelecer quantitativamente é a participação dos cavaleiros no poder local através do exercício do cargo de alvazil. Como se poderá comprovar num dos anexos deste trabalho, reuni os nomes de 56

26 Pedro Gomes BARBOSA, Povoamento e estrutura agricola na Estremadura central, Lisboa, Instituto Nacional de Investigação Científica, 1992, pp. 233-235. 
alvazis de Santarém, desde 1187. Destes, 39 pertencem à segunda metade do século XIII. Número muito razoável tendo em consideração os 50 anos em análise e os limites ao exercício do cargo. Dezassete são identificáveis como cavaleiros, o que resulta numa proporção entre cavaleiros e não cavaleiros, no alvazilato, de $44 \%$ e $56 \%$ respetivamente. Uma carta régia outorgada ao concelho de Santarém em $1292^{27}$, que determina sejam os homens bons eleitos para alvazis um cavaleiro e o outro cidadão, parece-me reforçar a justeza destes valores.

\subsection{Os cavaleiros e o poder}

Do que até aqui disse concluo, naturalmente, que Santarém exerce uma forte atração sobre a nobreza, embora maioritariamente sobre uma nobreza de filhos segundos e de ramos secundários. Mas já outros o fizeram antes. Vale a pena recordar Pedro de Azevedo, que em 1897, chamava a atenção para os frequentes casamentos que os nobiliários medievais registam com as "plebeias ricas de Santarém» ${ }^{28}$. E José Mattoso, que um século depois, num texto sobre os nobres nas cidades portuguesas da Idade Média, evidenciou escolherem muitos deles esta vila para casar e residir, construir propriedades de prestígio e servir o rei ${ }^{29}$.

Sobretudo servir o rei, pois servir o poder local, investidos na dignidade de alvazil parece interessar apenas a uma minoria: $12 \%$ do total de cavaleiros. O interessante é que cavaleiros por nascimento e cavaleiros vilãos participam de forma idêntica nesta minoria, o que a meu ver é mais um sinal da emulação destes em relação aqueles.

Esta questão da emulação é, como veremos uma das duas questôes chaves que coloquei. A outra questão, que não podia deixar de colocar sob pena de retirar vida e interesse a um trabalho de história social, é se os nobres de Santarém se limitavam a viver dos seus rendimentos materiais e simbólicos. Felizmente penso que posso dar uma resposta através da análise de um conjunto de onze documentos, distribuídos entre 1252 e 1305 , que permitem perceber um pouco o que era o concelho de Santarém, nesta época, enquanto orgão de poder. Deste grupo destaquei dois documentos.

${ }^{27}$ Pedro de AZEVEDO, "O trovador Martim Soares e seu filho João Martins", Revista Lusitana, 5 (1897), 114-136, n. 4.

28 Pedro de AZEVEDO, "O trovador Martim Soares e seu filho João Martins", Revista Lusitana, 5 (1897), pp. 119-121.

${ }^{29}$ José MATTOSO, “Os nobres nas cidades portuguesas da Idade Média”, Portugal medieval. Novas interpretaçôes, Lisboa, Imprensa Nacional - Casa da Moeda, 1985, pp. 281-290. 
Pelo primeiro documento, de $1294^{30}$, conhecemos em parte a composição da assembleia que decidiu da doação do paul de Magos ao rei. À cabeça dos 41 subscritores do documento final temos em primeiro lugar Fernando Dade, filho do alcaide-mor Martinho Dade; e a seguir:

- Gomes Pais da Silva, um nobre que é genro do dito alcaide-mor;

- o meirinho-mor do rei, João Simão;

- o mordomo do infante dom Afonso;

- o nosso já conhecido Rui Pais Bugalho, vassalo régio;

- vários cavaleiros por nascimento.

Pelo segundo documento, de $1305^{31}$, conhecemos igualmente em parte a composição da assembleia que decidiu da doação de outras importantes propriedades ao rei, no caso concreto as lezírias da Fraceira e da Atalaia. À cabeça dos 45 subscritores do documento final temos em primeiro lugar dom Pedro Eanes Portel, filho de João Peres de Aboim, rico homem, figura proeminente da corte; e a seguir:

- um futuro meirinho-mor de dom Dinis (1312-1318), Rodrigo Eanes Redondo;

- o almoxarife de Lisboa;

- um ex-almoxarife de Santarém (1302);

- um ex-alcaide de Santarém (1294-1296);

- vários cavaleiros por nascimento.

Respondendo então à questão colocada, os nobres de Santarém não se limitavam a viver dos seus rendimentos materiais e simbólicos. Estabeleciam a articulação entre o poder local e o poder central, permitindo, se não sempre, pelo menos quando importava, a subordinação do concelho aos interesses régios.

\subsection{A ideologia cavaleiresca: dom Silvestre Peres}

Voltemos agora à questão da emulação do modelo cultural nobre. Utilizo, para o efeito, o caso de Silvestre Peres, cavaleiro de Santarém. Graças, sobretudo, ao cartório do mosteiro de Alcobaça, possuímos várias dezenas de mençôes a esta personagem, que se espraiam por toda a segunda metade do século XIII ${ }^{32}$.

${ }^{30}$ Pedro de AZEVEDO, "O trovador Martim Soares e seu filho João Martins", Revista Lusitana, 5 (1897), 114-136, n. 7.

${ }^{31}$ João Pedro RIBEIRO, Dissertaçōes cronológicas..., tomo 1, n. ${ }^{\circ} 74$. Veja-se também a interpretação de José MATTOSO, 1988, vol. 2, pp. 172-173.

${ }^{32}$ Entre 1251 (ANTT, CHE, mç. 13, n. ${ }^{\circ}$ 251) e 1298 (ANTT, Chr. D. Dinis, liv. 3, fl. 3 e v.). Em 1305 já o mosteiro de Alcobaça está na posse de 30 astis de herdade no reguengo de Valada, os quais houve de Silvestre Peres, de Santarém (ANTT, Gavetas, 13-3-4). 
Por intermédio dos dois testamentos que mandou lavrar, em 1273 e $1295^{33}$, ficamos a saber ser o avô o estabelecedor de uma albergaria na freguesia de Marvila e serem os pais suficientemente importantes para terem sepultura no mosteiro alcobacense. Por estes e por outros documentos sabemos que casou duas vezes, a primeira com Maria Mendes ${ }^{34}$, antes mulher de Paio Mendes, e a segunda vez com Maria Eanes ${ }^{35}$, sempre sem descendência sobrevivente, o que contrasta com a sua família colateral numerosa. Um irmão de Silvestre Peres, de nome Domingos, detém o título de mestre, indicativo de dignidade eclesiástica ou formação académica.

Não são estes, contudo, os dados que permitem colocar a questão das origens familiares, embora já pressuponham alguma relevância socioeconómica das mesmas. Na realidade, são mais dados indiciais do que provas categóricas os argumentos que alinham a favor de uma origem familiar a partir do meio mercantil.

Indício importante, à partida, é a referência no testamento de 1295 aos pobres que moram na albergaria que foi do avô de Silvestre Peres. Deve tratar-se do mesmo instituto que algumas verbas adiante se localiza a par das casas que foram de Vasco Velho, no Ferragial, e constitui um legado a favor do hospital do Santo Espírito ${ }^{36}$. Como para a freguesia de Marvila, a que pertence a área do Ferragial, há notícia nesta época da existência de duas albergarias, uma de peliteiros e outra de mercadores, mas a primeira se situa na área da Porta da Atamarma, a albergaria de Silvestre Peres pode coincidir com a segunda, aliás denominada em data próxima pauperibus albergarie Mercatorum $(1297)^{37}$. Assim, estes pobres do Ferragial seriam mercadores pobres.

Por outro lado, o primeiro casamento da citada Maria Mendes, com Paio Mendes, remete-nos para um mercador com este nome registado em $1222^{38}$. Se a identificação for positiva, Maria Mendes teria casado suficientemente nova para vir a casar segunda vez com Silvestre Peres, por seu turno mais novo, e que também casa segunda vez. Uma sucessão de casamentos

${ }^{33}$ ANTT, $A L C, 1^{\text {a }}$ inc., mç. 14, n.o 2 (1273), ANTT, OSB, $A L C$, mç. 9, n.o 213 (1295).

${ }^{34}$ Silvestre Peres casado com dona Maria (Mendes) (ANTT, $A L C, 1^{\text {a }}$ inc., mç. 9, n.o 9).

35 Silvestre Peres casado com Maria Eanes (ANTT, $A L C$, $1^{\mathrm{a}}$ inc., mç. 18, n. ${ }^{\circ} 19$ ).

${ }^{36}$ Também ele de origem mercantil (e inspiração francicana). Veja-se Luís MATA, Ser, ter e poder. O hospital do Espirito Santo de Santarém nos finais da Idade Média, s. 1., Magno ediçōes - Câmara Municipal de Santarém, 2000, pp. 38-43.

${ }^{37}$ ANTT, $S D S, 1^{\text {a }}$ inc., mç. 1 , n. ${ }^{\circ} 18$.

${ }^{38}$ ANTT, SCS, mç. 1, n. ${ }^{\circ} 4$. 
inter-geracionais que deve, creio, ser vista como uma forma corrente de mobilidade social entre os escalóes superiores da vilania.

Um último indício reside no locativo frequentemente utilizado na identificação do nosso protagonista Silvestre Peres: «do Ferragial». O Ferragial é uma das áreas relacionadas com o desenvolvimento do núcleo comercial de Santarém, Marvila, e não admira que os mercadores de Santarém gostem de aí morar. Não são aliás os únicos, pois vizinhavam com alguns cavaleiros, como o citado Vasco Velho ${ }^{39}$. Ao longo do século XIII, por exemplo os mercadores Soeiro Pais ${ }^{40}$, Domingos Pais ${ }^{41}$, João Peres ${ }^{42}$ e João Eanes ${ }^{43}$, entre outros, utilizam o mesmo locativo. Este último, João Eanes, apresenta a particularidade de ser testamenteiro de Silvestre Peres, quer em 1273, quer em 1295. Além de vizinho, decerto um velho amigo.

O património fundiário do nosso micro-biografado compõe-se de prédios urbanos em Marvila e de um respeitável conjunto de propriedades rústicas, na área periurbana de Santarém (Enfesta dos Galhardos) e no seu termo (Tavra, Valada, Magos, vários locais da freguesia de São Pedro de Arrifana) ${ }^{44}$. Conjunto este extensível ao termo do concelho de Óbidos (Várzea de Martim Longo) ${ }^{45}$ e, além Tejo, à Vide, onde possuía um herdamento que deixará à ordem de Avis ${ }^{46}$.

São ainda aspetos importantes do percurso de Silvestre Peres o exercício do cargo de alvazil de Santarém pelo menos por três vezes, em 1273, 1282 e $1285^{47}$, as fortes ligações ao mosteiro de Alcobaça, do qual é foreiro ${ }^{48}$ e pres-

${ }^{39}$ Vasco Afonso Velho, cavaleiro (ANTT, $A L C$, $1^{\text {a }}$ inc., mç. 15, n. 31 - 1276).

${ }^{40}$ ANTT, $A L C, 1^{\text {a }}$ inc., mç. 7 , n. ${ }^{\circ} 6$ (1242).

${ }^{41}$ Bernardo Maria Godinho de Sá NOGUEIRA, Tabelionado e instrumento público em Portugal. Génese e implantação (1212-1279), dissertação de doutoramento em História, na área de especialização de Paleografia e Diplomática, apresentada à Faculdade de Letras da Universidade de Lisboa,1996, vol. 3, p. 119 (1262).

42 ANTT, $A L C, 1^{\text {a }}$ inc., mç. 16, n. ${ }^{\circ} 9$ (1277).

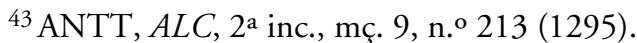

${ }^{44} \mathrm{Um}$ desses locais apresenta o sugestivo nome de Torre de Vilãos.

45 Pedro Gomes BARBOSA, Povoamento e estrutura agrícola na Estremadura central..., p. 232.

${ }^{46}$ ANTT, $O A V$, mç. 2, n. ${ }^{\circ} 256$.

47 Por exemplo: ANTT, Gavetas, 4-1-16 (1273); Pedro de AZEVEDO, "O trovador Martim Soares e sua família (documentos)”, Revista Lusitana, 21 (1918), 246-279, n. ${ }^{\circ} 2$ (1282); Pedro de AZEVEDO, "O trovador Martim Soares e seu filho João Martins", Revista Lusitana, 5 (1897), 124 (1285).

${ }^{48}$ ANTT, $A L C, 1^{\text {a }}$ inc., mç. 9, n.o 42 (1261). 
tameiro $^{49}$, que contempla generosamente nos seus testamentos e onde um sobrinho era monge, e as ligações à ordem de Avis, à qual, além do herdamento na Vide, deixa parte do seu equipamento militar, sendo a parte restante para outro sobrinho. Na qualidade de juiz escolhido pelas partes arbitra uma contenda entre esta ordem e dona Sancha Pais e seus filhos ${ }^{50}$. Na mesma qualidade de juiz, mas nomeado por carta régia, arbitra outra contenda envolvendo um herdamento localizado no reguengo da Azóia ${ }^{51}$. As suas ligaçōes visíveis com a coroa resumem-se a esta nomeação e ao conflito em que ele próprio contende com o rei sobre direitos numa parte do paul de Magos $^{52}$.

Vale a pena prestar um pouco mais de atenção à ligação à ordem militar de Avis. Sobre o herdamento da Vide, composto por moinhos, adega, vinhas e herdades, é-nos dito (no testamento de 1295) que foram de dom Martinho. Se se tratar, como tudo indica, de Martinho Fernandes, mestre de Avis, pode estar em causa um conjunto de bens cedido a título precário, em troca da prestação de serviço militar a cavalo. Ficaria assim igualmente explicada a separação da cota de malha (loriga) e das brafoneiras (proteções dos braços) do restante equipamento militar (perponto, escudo, espada, capelo e ascumas) que ia para o sobrinho. Tratava-se, nos dois casos, de devoluções à ordem, visto o cavaleiro não dispor da possibilidade de transmissão dos bens em linha reta.

Creio ter trazido alguma luz sobre as origens deste cavaleiro vilão: meio mercantil, papel desempenhado pelo mestre da ordem de Avis. Vejamos agora outros aspetos, de natureza social e ideológica, que reforçam a sua participação num modelo cultural nobre. Desde logo a rede de laços pessoais de que é o centro, com os seus familiares de sangue, o seu escudeiro, o seu capelão, os seus clientes e outros dependentes. Em benefício de todos eles segue, nos seus testamentos, o ritual de despojamento dos bens móveis. Muito reveladora do seu modo de vida é a terceira verba do seu testamento de 1295, logo após encomendar a sua alma a Deus e mandar enterrar o seu corpo em Alcobaça, com seu pais e irmãos, e legar 150 libras à igreja de

${ }^{49}$ Em 1276, os bens que traz Silvestre Peres em préstamo do mosteiro são exceptuados do arrendamento feito por seis anos de todos os bens da instituição em Santarém e seu termo a Pedro Esteves, almoxarife do rei na dita vila (ANTT, $A L C, 1^{\text {a }}$ inc., mç. 15, n. ${ }^{\circ}$ 36). O préstamo de Silvestre Peres era constituído pelos bens deixados a Alcobaça por seu irmão Mestre Domingos. Este também já trouxera em préstamo da mesma instituição uma casa no Ferragial, a qual é em 1256 doada a Martinho Fernandes, mestre da ordem de Avis (ANTT, $O A V$, mç. 2, n. ${ }^{\circ}$ 241).

${ }^{50}$ ANTT, $O A V$, mç. 2, n. ${ }^{\circ} 232$ (1277).

${ }^{51}$ ANTT, Gavetas, 3-3-6 (1290).

52 ANTT, Gavetas, 12-9-17 (1294). 
Marvila, donde era paroquiano. É dedicada aos seus "podengos com suas cadeias", ou seja, aos seus cães de caça. A fins mais elevados se destinam as verbas em que se propõe financiar um homem que queira ir a Jerusalém, se fizerem cruzada, e um peregrino que vá a Santiago de Compostela. Por fim, manda que depois de morto lhe metam o hábito de monge alcobacense. Nas suas próprias palavras: «coisa que eu sempre desejei». Palavras reveladoras da ideia do hábito monacal como casulo redentor que no corpo do cavaleiro une as duas ordens nobres da sociedade: a ordem dos bellatores e a ordem dos oratores.

\section{Conclusão}

Após séculos de equiparação jurídica e fiscal entre milites e infantionibus, nos finais do século XIII a nobreza exerce uma natural atração sobre os escalóes superiores da vilania, que decorre em paralelo com a sua própria urbanização. Este duplo fenómeno é confirmado pela imitação do modo de vida nobre e pelas estratégias matrimoniais seguidas, envolvendo com frequência elementos de famílias do meio mercantil. E, também, pela utilização da expressão "homens bons» para identificar os membros mais ricos e proeminentes da comunidade, incluindo cavaleiros de linhagem e cavaleiros vilãos. No fundo, estes dois grupos parecem articulados numa realidade comum, que se designa melhor por cavalaria urbana.

Em resposta à plebeização dos seus escalōes inferiores, a nobreza atuará redefinindo e reforçando a hierarquia social estabelecida recorrendo a uma categoria social baseada na ideia de nascimento, o "filho de algo», ou fidalgo. Detetada no caso português desde $1211^{53}$, em 1251 o rei reconhece o seu valor aristocrático: cum consilio suorum riquorum hominum et suorum filiorum de algo ${ }^{54}$. Esta reação aristocrática terá no século XIV como intérprete mais notável o já citado conde D. Pedro, que no prólogo ao seu Livro de linhagens (1340-1344) a vê como conducente à formação de uma consciência de classe: «fidalgos» ou "nobres fidalgos», "de grande poder», «iguais» ou «mais pequenos", «todos devem ser de um coração".

\footnotetext{
${ }^{53}$ José MATTOSO, Identificação de um país..., vol. 1, p. 110.

${ }^{54}$ Alexandre HERCULANO, Portugalia Monumenta Historica. Leges et consuetudines ..., vol. 1, p. 190.
} 
Apêndice 1

Cavaleiros de Santarém (1230-1300)

\begin{tabular}{|c|c|c|c|c|}
\hline Datas & extremas & Nome & $\begin{array}{l}\text { Classificado } \\
\text { como CPN }\end{array}$ & $\begin{array}{c}\text { Classificado } \\
\text { como CV }\end{array}$ \\
\hline - & - & Domingos Barata & & $\mathbf{x}$ \\
\hline- & - & Martinho Garcia & & $\mathbf{x}$ \\
\hline 1230 & 1241 & Martinho Peres Cotom & & $\mathbf{x}$ \\
\hline 1232 & 1232 & Pedro Pais (dom) & & $\mathbf{x}$ \\
\hline 1233 & 1247 & Estêvão Peres (I) & & $\mathbf{x}$ \\
\hline 1234 & 1241 & Pedro Galego & & $\mathbf{x}$ \\
\hline 1237 & 1271 & Martinho Vasques & & $\mathbf{x}$ \\
\hline 1240 & 1256 & João Gomes (dom) & & $\mathbf{x}$ \\
\hline 1242 & 1242 & Hooricus Eanes & & $\mathbf{x}$ \\
\hline 1242 & 1242 & Fernando Rodrigues (de Seserigo) & & $\mathbf{x}$ \\
\hline 1243 & 1243 & Pedro Soares (dom) & & $\mathbf{x}$ \\
\hline 1243 & 1243 & João Miguéis de [Canha] & & $\mathbf{x}$ \\
\hline 1246 & 1251 & João Nunes (do Ferragial) & & $\mathbf{x}$ \\
\hline 1248 & 1265 & Fernando Martins Corutelo & $\mathbf{x}$ & \\
\hline 1249 & 1280 & João Peres de Aboim (dom) & $\mathbf{x}$ & \\
\hline 1249 & 1255 & Martinho Gonçalves & & $\mathbf{x}$ \\
\hline 1249 & 1294 & João Viegas & & $\mathbf{x}$ \\
\hline 1249 & 1257 & Aires Peres (dom) & & $\mathbf{x}$ \\
\hline 1249 & 1282 & João Esteves & & $\mathbf{x}$ \\
\hline 1249 & 1275 & Martinho Gonçalves Charamela & & $\mathbf{x}$ \\
\hline 1251 & 1283 & Martinho Martins Dade & $\mathbf{x}$ & \\
\hline 1251 & 1298 & Silvestre Peres (do Ferragial) & & $\mathbf{x}$ \\
\hline 1250 & 1255 & Raimundo Viegas & & $\mathbf{x}$ \\
\hline 1252 & 1258 & Vasco Vicente & & $\mathbf{x}$ \\
\hline 1252 & 1268 & Mendo Caçapo (Cazapo) & $\mathbf{x}$ & \\
\hline 1252 & 1259 & Domingos Martins & & $\mathbf{x}$ \\
\hline 1252 & 1262 & $\begin{array}{l}\text { Fernando Soares Vargalho (Var- } \\
\text { galom) }\end{array}$ & & $\mathbf{x}$ \\
\hline 1252 & 1270 & Rodrigo Mendes (I) & & $\mathbf{x}$ \\
\hline 1253 & 1264 & Gomes Peres de Alvarenga & $\mathbf{x}$ & \\
\hline 1253 & 1274 & Mestre Vicente & & $\mathbf{x}$ \\
\hline 1254 & 1258 & Gil Peres & & $\mathbf{x}$ \\
\hline 1254 & 1261 & Mendo Gonçalves (dom) & & $\mathbf{x}$ \\
\hline 1254 & 1264 & João Domingues & & $\mathbf{x}$ \\
\hline 1254 & 1254 & Paio Fernandes & & $\mathbf{x}$ \\
\hline 1254 & 1254 & Miguel Fernandes & & $\mathbf{x}$ \\
\hline
\end{tabular}




\begin{tabular}{|c|c|c|c|c|}
\hline Datas & extremas & Nome & $\begin{array}{l}\text { Classificado } \\
\text { como CPN }\end{array}$ & $\begin{array}{c}\text { Classificado } \\
\text { como CV }\end{array}$ \\
\hline 1254 & 1254 & Afonso Domingues & & $\mathbf{x}$ \\
\hline 1255 & 1255 & Fernando Eanes & & $\mathbf{x}$ \\
\hline 1253 & 1263 & Gonçalo Navalha & $\mathbf{x}$ & \\
\hline 1255 & 1255 & Vicente Infante & & $\mathbf{x}$ \\
\hline 1255 & 1255 & Rodrigo Vasques & & $\mathbf{x}$ \\
\hline 1255 & 1291 & Pedro Fernandes & & $\mathbf{x}$ \\
\hline 1255 & 1255 & Fernando Fernandes de $[. .]$. & & $\mathbf{x}$ \\
\hline 1256 & 1256 & Martinho Peres do Casal & $\mathbf{x}$ & \\
\hline 1256 & 1256 & Fernando Esteves & & $\mathbf{x}$ \\
\hline 1259 & 1259 & Paio Soares & & $\mathbf{x}$ \\
\hline 1259 & 1259 & Nuno Mendes & & $\mathbf{x}$ \\
\hline 1259 & 1281 & Tibúrcio Martins & & $\mathbf{x}$ \\
\hline 1260 & 1260 & Miguel Soares & & $\mathbf{x}$ \\
\hline 1260 & 1260 & Pedro Gil & & $\mathbf{x}$ \\
\hline 1260 & 1260 & Paio Moniz & & $\mathbf{x}$ \\
\hline 1260 & 1260 & João Moniz & & $\mathbf{x}$ \\
\hline 1260 & 1260 & Domingos Eanes & & $\mathbf{x}$ \\
\hline 1260 & 1275 & Geraldo Soares & & $\mathbf{x}$ \\
\hline 1260 & 1260 & João Mendes & & $\mathbf{x}$ \\
\hline 1260 & 1260 & Pedro Afonso & & $\mathbf{x}$ \\
\hline 1260 & 1260 & Estêvão Peres de Aboim & $\mathbf{x}$ & \\
\hline 1261 & 1261 & Lourenço Eanes & & $\mathbf{x}$ \\
\hline 1261 & 1269 & Fernando Fernandes Cogominho & $\mathbf{x}$ & \\
\hline 1261 & 1269 & Pedro Martins Casével & & $\mathbf{x}$ \\
\hline 1261 & 1284 & Geraldo Rodrigues & & $\mathbf{x}$ \\
\hline 1261 & 1261 & Martinho Peres & $\mathbf{x}$ & \\
\hline 1262 & 1262 & Mendo Esteves & & $\mathbf{x}$ \\
\hline 1262 & 1262 & Vicente Gil & & $\mathbf{x}$ \\
\hline 1264 & 1264 & João Lourenço & & $\mathbf{x}$ \\
\hline 1264 & 1264 & Gonçalo Pais & & $\mathbf{x}$ \\
\hline 1265 & 1265 & Paio Viegas & & $\mathbf{x}$ \\
\hline 1265 & 1282 & João Mendes Lofino & & $\mathbf{x}$ \\
\hline 1266 & 1285 & Martinho Eanes de Fremoselhe & $\mathbf{x}$ & \\
\hline 1267 & 1267 & Mendo Peres Pestana & $\mathbf{x}$ & \\
\hline 1268 & 1278 & Estêvão Gonçalves & & $\mathbf{x}$ \\
\hline 1269 & 1282 & João Martins (da Alcáçova) & & $\mathbf{x}$ \\
\hline 1269 & 1269 & Martinho Peres de Barbosa & $\mathbf{x}$ & \\
\hline 1269 & 1303 & João Martins Trovador & $\mathbf{x}$ & \\
\hline 1270 & 1270 & João de Roma & & $\mathbf{x}$ \\
\hline 1271 & 1271 & João Vicente & & $\mathbf{x}$ \\
\hline
\end{tabular}




\begin{tabular}{|c|c|c|c|c|}
\hline Datas & extremas & Nome & $\begin{array}{l}\text { Classificado } \\
\text { como CPN }\end{array}$ & $\begin{array}{c}\text { Classificado } \\
\text { como CV }\end{array}$ \\
\hline 1271 & 1277 & Vasco Peres & & $\mathbf{x}$ \\
\hline 1271 & 1271 & Miguel Mendes & $\mathbf{x}$ & \\
\hline 1272 & 1305 & Rodrigo Pais Bugalho & $\mathbf{x}$ & \\
\hline 1272 & 1282 & Martinho Mendes Maça & $\mathbf{x}$ & \\
\hline 1273 & 1273 & Gomes Peres & $\mathbf{x}$ & \\
\hline 1274 & 1274 & Martinho Esteves (de Abrantes) & & $\mathbf{x}$ \\
\hline 1274 & 1274 & João Gomes Barreto & $\mathbf{x}$ & \\
\hline 1275 & 1283 & Rodrigo Peres & $\mathbf{x}$ & \\
\hline 1275 & 1285 & Martinho Afonso & & $\mathbf{x}$ \\
\hline 1275 & 1275 & Lourenço Dias & & $\mathbf{x}$ \\
\hline 1275 & 1276 & Vasco Afonso Velho (do Ferragial) & & $\mathbf{x}$ \\
\hline 1275 & 1275 & Pedro Fernandes Eyxamuz & & $\mathbf{x}$ \\
\hline 1275 & 1275 & Egas Lourenço, de Alvares & $\mathbf{x}$ & \\
\hline 1275 & 1275 & Martinho Esteves & & $\mathbf{x}$ \\
\hline 1275 & 1275 & João Esteves & & $\mathbf{x}$ \\
\hline 1276 & 1276 & Martinho Fernandes & & $\mathbf{x}$ \\
\hline 1276 & 1276 & Abril Peres & & $\mathbf{x}$ \\
\hline 1278 & 1313 & Soeiro Mendes Petite & $\mathbf{x}$ & \\
\hline 1280 & 1285 & Estêvão Peres (II) & & $\mathbf{x}$ \\
\hline 1280 & 1280 & Gonçalo Esteves, de Alvares & $\mathbf{x}$ & \\
\hline 1280 & 1294 & Afonso Pais Bugalho & $\mathbf{x}$ & \\
\hline 1281 & 1282 & Gomes Peres Petarinho & $\mathbf{x}$ & \\
\hline 1281 & 1282 & Estêvão Eanes & $\mathbf{x}$ & \\
\hline 1281 & 1314 & Rodrigo Pais Viegas & $\mathbf{x}$ & \\
\hline 1281 & 1281 & Rodrigo Gomes Colmeeiro & $\mathbf{x}$ & \\
\hline 1281 & 1281 & Soeiro Gomes Colmeeiro & $\mathbf{x}$ & \\
\hline 1281 & 1281 & Rodrigo Dias & $\mathbf{x}$ & \\
\hline 1281 & 1281 & João Martins (outro) & & $\mathbf{x}$ \\
\hline 1281 & 1281 & Gomes Lourenço Petarinho & $\mathbf{x}$ & \\
\hline 1281 & 1281 & Egas Lourenço & $\mathbf{x}$ & \\
\hline 1282 & 1282 & Rodrigo Pais & & $\mathbf{x}$ \\
\hline 1282 & 1282 & João Aires (I) & & $\mathbf{x}$ \\
\hline 1282 & 1282 & Martinho Eanes & $\mathbf{x}$ & \\
\hline 1282 & 1285 & João Martins Botelho & $\mathbf{x}$ & \\
\hline 1283 & 1299 & Rodrigo Mendes (II) & & $\mathbf{x}$ \\
\hline 1284 & 1284 & Diogo Alvites & & $\mathbf{x}$ \\
\hline 1284 & 1284 & Martinho Carpinteiro & & $\mathbf{x}$ \\
\hline 1284 & 1284 & Pedro Esteves & & $\mathbf{x}$ \\
\hline 1284 & 1289 & João Freire & $\mathbf{x}$ & \\
\hline 1285 & 1285 & Martinho Vasques Cetariom & & $\mathbf{x}$ \\
\hline
\end{tabular}




\begin{tabular}{|c|c|c|c|c|}
\hline Datas & extremas & Nome & $\begin{array}{l}\text { Classificado } \\
\text { como CPN }\end{array}$ & $\begin{array}{c}\text { Classificado } \\
\text { como CV }\end{array}$ \\
\hline 1286 & 1286 & Afonso Peres Petarinho & $\mathbf{x}$ & \\
\hline 1286 & 1286 & Paio Álvares & $\mathbf{x}$ & \\
\hline 1289 & 1289 & Rodrigo Vasques [Pimentel] & $\mathbf{x}$ & \\
\hline 1289 & 1289 & Aires Pais & & $\mathbf{x}$ \\
\hline 1289 & 1289 & Martinho Martins, de (...) & & $\mathbf{x}$ \\
\hline 1289 & 1289 & Martinho Mendes da Silveira & & $\mathbf{x}$ \\
\hline 1290 & 1292 & Vasco Peres Froiaz & $\mathbf{x}$ & \\
\hline 1290 & 1315 & Gonçalo Esteves de Aboim & $\mathbf{x}$ & \\
\hline 1294 & 1294 & João Aires (II) & & $\mathbf{x}$ \\
\hline 1294 & 1296 & Estêvão Peres Lobato & $\mathbf{x}$ & \\
\hline 1294 & 1296 & Lourenço Eanes Bochardo & $\mathbf{x}$ & \\
\hline 1294 & 1294 & Fernando Dade & $\mathbf{x}$ & \\
\hline 1294 & 1294 & Gonçalo Martins do Casal & $\mathbf{x}$ & \\
\hline 1294 & 1294 & $\begin{array}{l}\text { Rodrigo Martins do Casal, seu } \\
\text { irmão }\end{array}$ & $\mathbf{x}$ & \\
\hline 1294 & 1294 & Rodrigo Eanes Redondo & $\mathbf{x}$ & \\
\hline 1294 & 1298 & Estêvão Eanes de Pauha & $\mathbf{x}$ & \\
\hline 1294 & 1294 & Martinho Vasques Cechorinho & $\mathbf{x}$ & \\
\hline 1294 & 1294 & Estêvão Fernandes Barreto & $\mathbf{x}$ & \\
\hline 1294 & 1294 & Fernando Rodrigues Bugalho & $\mathbf{x}$ & \\
\hline 1294 & 1294 & Gomes Pais da Silva & $\mathbf{x}$ & \\
\hline 1295 & 1296 & Gil Garcia Malhaqueija & & $\mathbf{x}$ \\
\hline 1295 & 1295 & Afonso Moniz & & $\mathbf{x}$ \\
\hline 1295 & 1295 & Fernando Peres & & $\mathbf{x}$ \\
\hline 1296 & 1296 & Geraldo Faria & & $\mathbf{x}$ \\
\hline 1299 & 1299 & Fernando Martins & & $\mathbf{x}$ \\
\hline 1299 & 1310 & Pedro Eanes de Pauha & $\mathbf{x}$ & \\
\hline
\end{tabular}

$\mathrm{CPN}$ = cavaleiro por nascimento.

$\mathrm{CV}$ = cavaleiro vilão. 
Apêndice 2

Alvazis de Santarém (1187-1300)

\begin{tabular}{|c|c|c|}
\hline \multicolumn{2}{|c|}{ Datas extremas } & \multirow[b]{2}{*}{ Salvador Soares } \\
\hline 1187 & 1187 & \\
\hline 1199 & 1199 & Egas Pais \\
\hline 1199 & 1199 & João Nunes \\
\hline 1199 & 1199 & Paio Peres \\
\hline 1199 & 1199 & Fernando Nunes \\
\hline 1214 & 1214 & Pedro Vasques \\
\hline 1214 & 1214 & Domingos Eanes \\
\hline 1218 & 1218 & Gomes Egas \\
\hline 1237 & 1237 & Pedro Eanes (I) \\
\hline 1240 & 1240 & Mendo Dias \\
\hline 1240 & 1240 & Pedro Pais \\
\hline 1243 & 1243 & Domingos Peres da Maia \\
\hline 1246 & 1255 & Martinho Peres \\
\hline 1246 & 1246 & Gonçalo Rodrigues \\
\hline 1249 & 1252 & Rodrigo Geraldes \\
\hline 1249 & 1275 & João Esteves \\
\hline 1250 & 1250 & Martinho Esteves \\
\hline 1251 & 1261 & João Peres (I) \\
\hline 1252 & 1258 & João de Sela \\
\hline 1254 & 1261 & Mendo Gonçalves \\
\hline 1258 & 1258 & João Peres da Amiga \\
\hline 1260 & 1260 & Lourenço Martins \\
\hline 1260 & 1260 & Martinho Vicente \\
\hline 1261 & 1282 & Geraldo Rodrigues \\
\hline 1262 & 1262 & Ordonho Martins \\
\hline 1270 & 1270 & Rodrigo Mendes \\
\hline 1271 & 1271 & Munio Mendes \\
\hline 1271 & 1272 & Pedro Mendes Lupo \\
\hline 1273 & 1285 & Silvestre Peres \\
\hline 1273 & 1277 & Vasco Afonso Velho \\
\hline 1275 & 1275 & Martinho Mendes Maça \\
\hline 1275 & 1289 & Filipe Guilherme \\
\hline 1275 & 1286 & Vasco Peres \\
\hline 1277 & 1277 & Pedro Eanes (II) \\
\hline 1281 & 1282 & Rodrigo Peres \\
\hline 1281 & 1281 & Gomes Lourenço Petarinho \\
\hline
\end{tabular}




\begin{tabular}{|c|c|c|}
\hline \multicolumn{2}{|c|}{ Datas extremas } & Nome \\
\hline 1281 & 1282 & Estêvão Gomes \\
\hline 1281 & 1281 & [...] Soares \\
\hline 1282 & 1282 & Estêvão Ramos \\
\hline 1283 & 1283 & João Martins Botelho \\
\hline 1284 & 1284 & João Aires (I) \\
\hline 1284 & 1285 & João Fernandes \\
\hline 1286 & 1286 & João Domingues \\
\hline 1286 & 1286 & Afonso Peres Petarinho \\
\hline 1288 & 1288 & João Eanes \\
\hline 1288 & 1294 & João Martins Trovador \\
\hline 1289 & 1289 & Rodrigo Pais \\
\hline 1290 & 1290 & Afonso Rodrigues Badim \\
\hline 1290 & 1291 & João Gomes \\
\hline 1294 & 1294 & Geraldo Marques \\
\hline 1296 & 1306 & Afonso Guilherme \\
\hline 1296 & 1296 & João Aires (II) \\
\hline 1298 & 1298 & Estêvão Eanes de Pauha \\
\hline 1299 & 1316 & Fernando Martins \\
\hline 1299 & 1299 & Martinho Eanes \\
\hline 1299 & 1310 & Pedro Eanes de Pauha \\
\hline
\end{tabular}


Siglas e abreviaturas utilizadas:

a) arquivos

ANTT: Instituto dos Arquivos Nacionais / Torre do Tombo

b) fundos

ALC: mosteiro de Santa Maria de Alcobaça

ALM: mosteiro de Santa Maria de Almoster

CHE: mosteiro de Santa Maria de Chelas

Chr.: Chancelaria

Gavetas: Gavetas da Torre do Tombo

OAV: Ordem de Avis

OSB: Ordem de São Bernardo

SCS: mosteiro de Santa Clara de Santarém

SDS: mosteiro de São Domingos de Santarém

SMA: igreja de Santa Maria da Alcáçova de Santarém

b) publicações

DHCL. LIM1949 / DHCL. LII1949: Documentos para a história da cidade de Lisboa. Livro I de misticos. Livro II del rei dom Fernando. 